suggests a cumulative dose-related or time-related effect, or both. Nevertheless, many patients have taken up to $32 \mathrm{~g}$ daily for long periods without developing myopathy ${ }^{1}$ or acute renal failure, suggesting an idiosyncratic response. ${ }^{2}$ Other reports of acute renal failure $^{3}{ }^{4}$ after aminocaproic acid leave doubt about the mechanism concerned. None of the patients had the associated acute massive muscle necrosis seen in our case. We did not find myoglobin in either plasma or urine, so that this was unlikely to have been the mechanism of the acute renal failure. The overwhelming catabolism associated with myonecrosis might have created a crystallopathy with uric acid excretion, which may precipitate renal failure. Though renal function was reversible, aminocaproic acid may have a direct nephrotoxic effect, as evidenced by the disappearance of proteinuria ${ }^{5}$ on withdrawing the drug or reducing the dosage. No abnormalities of fibrin turnover or coagulation were detected, so that intravascular coagulation was unlikely. Renal biopsy was not performed because of the patient's respiratory impairment.

In view of the increasing emphasis on aminocaproic acid to control subarachnoid haemorrhage doctors should be aware of the possible consequences of such treatment. We propose routine measurement of creatine kinase activity and urine analysis in patients receiving long-term treatment.

We thank Mr J Moore-Robertson for allowing us to report this case, and Mr F Harper, Central Clinical Laboratory, for biochemical help. We also thank Miss M A Alston and Mrs J Harrison for secretarial work.

${ }^{1}$ Lane RJM, Mastaglia FL. Drug-induced myopathies in man. Lancet 1978 ;ii :562.

2 Lane RJM, Martin AM, McLelland NJ, Mastaglia FL. Epsilon aminocaproic acid (EACA) myopathy. Postgrad Med $\mathcal{f} 1979 ; 55: 282-5$.

3 Charyton C, Purtilo D. Glomerular capillary thrombosis and acute renal failure after epsilon aminocaproic acid therapy. $N$ Engl f Med 1969; 280:1102-4.

4 Stark SN, White JG, Langer LJR, Krivit W. Epsilon amino caproic acid therapy as a cause of intrarenal obstruction in haematuria of haemophiliacs. Scand $\mathcal{F}$ Haematol $1965 ; 2$ :99-107.

${ }^{5}$ Frank MM, Sergent JS, Kane MA, Alling DW. Epsilon aminocaproic acid therapy of hereditary angioneurotic edema. $N$ Engl $\mathcal{f}$ Med 1972; 286: 808-12.

(Accepted 15 April 1980)

Renal Unit, North Ormesby Hospital, Middlesbrough TS3 6HJ

C K BISWAS, MB, MRCP, registrar in renal and general medicine

D A REID MILLIGAN, $\mathrm{MB}$, $\mathrm{CHB}$, senior house officer in renal medicine $S$ D AGTE, $M B$, BS, senior house officer in renal medicine

D H KENWARD, MB, MRCP, consultant nephrologist

Department of Neurology, General Hospital, Middlesbrough TS5 $5 A Z$

P J B TILLEY, MB, MRCP, consultant neurologist

\section{Avascular necrosis of bone in children receiving high-dose steroid treatment}

Many reports ${ }^{1}$ have noted a possible association between steroid treatment and avascular necrosis of bone, but the exact relation remains unclear. We believe that the cases reported may have been examples of idiopathic avascular necrosis of bone in patients who coincidentally had undergone or were undergoing steroid treatment. Study of these and other cases shows that most patients had received steroid treatment for conditions themselves associated with avascular necrosis of bone or known to produce a radiographic appearance that might be confused with this condition-for example, rheumatoid arthritis, systemic lupus erythematosus, and after renal transplantation for chronic renal failure. In renal transplantation many factors may produce radiographic changes similar to those seen in avascular necrosis of bone-for example, osteomalacia, osteoporosis, and secondary and tertiary hyperparathyroidism.

No report exists of the incidence of avascular necrosis of bone in children receiving high-dose steroid treatment who have not undergone transplantation. We studied 28 such children with the nephrotic syndrome because this disease is of acute onset and has a low association with other forms of metabolic bone disease. Furthermore, these children rarely develop chronic renal failure and therefore do not undergo renal transplantation.

\section{Patients, methods, and results}

We contacted 28 children who had been treated with high doses of prednisone for renal disease (nephrotic syndrome 24 patients, HenochSchönlein nephritis two, and post-streptococcal nephritis two). All were well when examined; none had renal failure.

By using a standardised technique anteroposterior and lateral radiographs of both hips and knees were obtained, which included the upper and lower thirds of the femoral shaft and the upper third of the tibial shaft. The radiographs were analysed blind by a radiologist and two orthopaedic surgeons, two of whom had special experience of the radiographic appearances of avascular necrosis of bone.

Steroid treatment was started at from 1 to 11 years (mean \pm SD $4.5 \pm 2 \cdot 9$ ). Ages at radiographic examination ranged from 4 to 20 years (mean $12 \cdot 6 \pm 5 \cdot 0$ ). The interval between these two events was one to 16 years (mean $8.0 \pm 3.9$ ) One patient was still undergoing steroid treatment when examined radiographically; in the remaining 27 the interval between stopping steroids and radiographic examination was one to 18 years (mean $6 \cdot 3 \pm 3 \cdot 9$ ). The initial dosage of prednisone given to all patients was $2 \mathrm{mg} / \mathrm{kg} /$ day (maximum $60 \mathrm{mg} /$ day); subsequent dosage depended on the response to treatment The cumulative dose ranged from 2.0 to $63.9 \mathrm{~g}$ (mean $6.9+11.7 \mathrm{~g}$-table) In addition 12 children received cyclophosphamide $2-4 \mathrm{mg} / \mathrm{kg} /$ day for two to three months. None of the radiographs contained any evidence of osteonecrosis.

Cumulative prednisone dose in 28 children studied

\begin{tabular}{lllllllllll}
\hline Prednisone dose $(\mathrm{g})$ & $0-$ & $2-$ & $4-$ & $6-$ & $8-$ & $10-$ & $12-$ & $14-$ & $16-$ \\
No of children & $\cdots$ & 7 & 4 & 5 & 4 & 6 & & & & 2 \\
\hline
\end{tabular}

\section{Comment}

The steroid dosage used in these children was similar to that given to children receiving kidney transplants, in $25 \%$ of whom a prospective study $^{2}$ showed radiographic evidence of osteonecrosis. The longest interval between starting treatment and onset of osteonecrosis in transplant patients is about three years, ${ }^{3}$ which had been passed in 25 of our cases; we therefore assume our nil incidence of avascular necrosis of bone to be correct, though the reasons for it are not clear. Most of the children were aged 10 or under during treatment, whereas in the transplant study ${ }^{2}$ all but one of the cases of avascular necrosis of bone occurred in children over 10; age during treatment may be important. The time over which the cumulative steroid dose is given and the rate at which the dose is changed may possibly be more important than the actual cumulative dose. In two other studies 5 the incidence of avascular necrosis of bone in children receiving steroids after renal transplantation was about $10 \%$ and, interestingly, steroid dosage was not significantly different between the children with and without the condition. Thus we suggest that in patients undergoing renal transplantation for chronic renal failure other factors may be more important than steroid treatment in the development of avascular necrosis of bone.

We wish to thank Dr P M Hacking and staff of the department of radiology, Royal Victoria Infirmary, Newcastle upon Tyne.

${ }^{1}$ Pietrograndi V, Mastromarino R. Osteopatia da prolungato trattamento cortisonico. Ortopedia e Traumatologia dell' Apparato Motore 1957;25: 791-810.

2 Stern PJ, Watts HG. Osteonecrosis after renal transplantation in children. F Bone foint Surg 1979;61A:851-6.

${ }^{3}$ Catto M. Pathology of aseptic necrosis. In: Davidson JK, ed. Aseptic necrosis of bone. Amsterdam: Excerpta Medica, 1976:3-100.

${ }^{4}$ Uittenbogaart $\mathrm{CH}$, Isaacson MD, Stanley $\mathrm{P}$, et al. Aseptic necrosis after renal transplantation in children. Am $\mathcal{F}$ Dis Child 1978;132:765-7.

5 Potter DE, Genant HK, Salvatierra O. Avascular necrosis of bone after renal transplantation. Am $\mathcal{F}$ Dis Child 1978;132:1125-9.

(Accepted 15 April 1980)

Royal Victoria Infirmary, Newcastle upon Tyne NE1 4LP

P J GREGG, MD, FRCs, lecturer in orthopaedic surgery

M K BARSOUM, FRCS, orthopaedic registrar

D SOPPITT, MB, FRCR, consultant radiologist

R H JACKSON, BM, FRCP, consultant paediatrician 